\title{
Towards understanding the traits contributing to performance of pearl millet open-pollinated varieties in phosphorus-limited environments of West Africa
}

\author{
Dorcus C. Gemenet • Francesca Beggi • C. Tom Hash • Ousmane Sy • Mousa D. Sanogo • \\ Roger G. Zangre • Hamidou Falalou • Andreas Buerkert • Bettina I. G. Haussmann
}

Received: 31 December 2014 / Accepted: 7 August 2015 /Published online: 18 August 2015

(C) Springer International Publishing Switzerland 2015

\begin{abstract}
Aims Pearl millet [Pennisetum glaucum (L.) R. Br.] open-pollinated varieties, which are the predominant cultivars, have never been systematically evaluated for adaptation to low-soil phosphorus (P), a major constraint on pearl millet production in West Africa (WA). Methods We evaluated grain yield (GY), flowering time (FLO), harvest index (HI), and residual grain yields (RGY) of 102 open-pollinated varieties from WA under low-P $(-\mathrm{P})$ and high-P $(+\mathrm{P})$ field conditions in six environments of WA. In addition, PE-related traits of the varieties were evaluated at early growth stage in a pot experiment.

Results Significant genetic variation was observed for GY, FLO, HI and PE-related traits. P-efficient varieties
\end{abstract}

Responsible Editor: Tim S. George.

Electronic supplementary material The online version of this article (doi:10.1007/s11104-015-2636-9) contains supplementary material, which is available to authorized users.

D. C. Gemenet $(\bowtie) \cdot$ B. I. G. Haussmann

Institute of Plant Breeding, Seed Science and Population Genetics, University of Hohenheim, Fruwirthstr. 21, 70599 Stuttgart,

Germany

e-mail: gemenet2014@gmail.com

D. C. Gemenet

e-mail: chepkesis@yahoo.com

D. C. Gemenet

Kenya Agricultural and Livestock Research Organization, PO Box 57811, Nairobi 00200, Kenya had higher yield under $-\mathrm{P}$ conditions. Varietal performance under $-\mathrm{P}$ varied across environments depending on FLO, relative flowering delay under $-\mathrm{P}$ (FD) and RGY measured in the field. Low-P-susceptible varieties had higher FLO, lower HI than low-P-tolerant varieties. Response to direct selection under $-\mathrm{P}$ field conditions was $20.1 \mathrm{~g} \mathrm{~m}^{-2}$, whereas indirect selection response under $+\mathrm{P}$ was $16.3 \mathrm{~g} \mathrm{~m}^{-2}$.

Conclusions Selection under $-\mathrm{P}$ field conditions while taking into account seasonal variations for FLO, FD and $\mathrm{PE}$ is expected to be important for improving GY specifically targeting $-\mathrm{P}$ environments in WA.

Keywords Pearl millet Phosphorus efficiency - West Africa $\cdot$ Selection strategy

F. Beggi · A. Buerkert

Organic Plant Production and Agro-Ecosystems Research in the Tropics and Subtropics, University of Kassel, Witzenhaussen, Germany

C. T. Hash $\cdot$ H. Falalou International Crops Research Institute for the Semi-Arid Tropics (ICRISAT) Sahelian Centre, Niamey, Niger

O. Sy

Institut Sénégalais de Recherches Agricoles (ISRA), Bambey, Senegal

M. D. Sanogo

Institut d'Economie Rurale (IER), Cinzana, Mali

R. G. Zangre

Institut de l'Environnement et de Recherches Agricoles (INERA), Ouagadougou, Burkina Faso 


\section{Introduction}

About eleven million people are food insecure in Sahelian West Africa (WA; FAO et al. 2013) to which rapid population increases in this region with lacking widespread yield increases in staple crops such as pearl millet greatly contributes (de Rouw 2004). This trend is expected to persist especially with the vulnerability of smallholder Sahelian WA farmers to the likely effects of climate change which is expected to cause a further 10$15 \%$ decrease in pearl millet yields (Jarvis et al. 2011; Knox et al. 2011; Haussmann et al. 2012). Pearl millet is the only crop that can grow in some of the hottest and driest areas and as a result it is an important contributor towards food security in most arid and semi-arid regions of Asia and Africa (Mariac et al. 2006; Supriya et al. 2011). In addition to providing calories, pearl millet has been shown to contribute towards nutritional quality since its grain has been reported to have higher levels of zinc and iron than most cereals (Birner et al. 2007; Rai et al. 2012, 2014; Bashir et al. 2013, 2014; Pucher et al. 2014). In Sahelian WA, pearl millet grows under conditions of drought, high temperatures, low water holding capacity as well as poor soil fertility (Brück et al. 2003).

Low soil phosphorus $(\mathrm{P})$ is a major factor limiting crop production in the tropics and subtropics (Ramaekers et al. 2010; Lynch 2011; Bayuelo-Jiménez and Ochoa-Cadavid 2014) which is particularly pronounced in WA (Bationo et al. 1992, 1993; Rebafka et al. 1993). This is because the soils have low levels of plant available $\mathrm{P}$ and could have high potential for $\mathrm{P}$ fixation due to mineral compositions high in iron and aluminum composites (Hash et al. 2002). P is an important macronutrient for all living organisms as a constituent of nucleic acids, phospholipids and adenosine triphosphate (ATP) molecules (King et al. 2013; Hufnagel et al. 2014). $P$ fertilizer use is very low in WA $(<5 \mathrm{~kg} \mathrm{P}$ $\mathrm{ha}^{-1}$; Obersteiner et al. 2013) as a consequence of limited access due to poor infrastructure (Valluru et al. 2010) and lack of purchasing power by the smallholder farmers due to increasing fertilizer prices (Cordell et al. 2009) and volatility of market prices for millet grain. One approach towards solving this issue is by improving P efficiency of crop plants. The ability of a crop to produce biomass or yield under given $\mathrm{P}$ supply conditions is referred to as P efficiency (PE; Wissuwa et al. 2009; Wang et al. 2010) which is in turn divided into $P$ acquisition efficiency (PAE; ability to take up P from the soil) and $\mathrm{P}$ utilization efficiency (PUE; amount of biomass produced per unit $\mathrm{P}$ taken up; Wang et al. 2010; Veneklaas et al. 2012). Pearl millet adaptation to $\mathrm{P}$ deficiency therefore is an important breeding objective in WA.

A wide range of landrace-derived inbred lines and their testcrosses were recently evaluated for performance under low-P conditions in WA (Gemenet et al. 2014). In addition, the inbred lines were evaluated for $P$ uptake and P utilization efficiency under pot and field conditions (Gemenet et al. 2015). However pearl millet is cross pollinated in nature with more than $85 \%$ outcrossing rates (Burton 1974; Velu et al. 2011). Openpollinated varieties are the predominant cultivars in this region (Haussmann et al. 2012) and inbred lines developed from such varieties are prone to inbreeding depression. It is therefore possible that some of the observed variation among inbred lines could be a result of varying degrees of inbreeding depression. Evaluation of openpollinated varieties under low-P would therefore serve to validate the results obtained from pearl millet inbred lines evaluation and to refine breeding strategies targeting low-P adaptation. Furthermore, varieties selected under low-P can be used directly by farmers under low-P conditions. The objectives of this study therefore were

i) To estimate quantitative-genetic parameters for grain yield and flowering time of a wide range of WA pearl millet landrace and improved openpollinated varieties under contrasting P-fertilization levels in multi-location field trials and thereby to investigate possible low-P adaption mechanisms;

ii) To determine the relationship between grain yield under field conditions and early growth stage $\mathrm{P}$ use efficiency traits measured under pot trial conditions;

iii) To identify potential varieties with higher grain yield under low-P conditions that might be recommended to farmers in WA;

iv) To make inferences with regard to breeding activities targeting low-P environments in WA.

\section{Materials and methods}

Genetic materials

The study involved 46 original pearl millet [Pennisetum glaucum (L.) R. Br syn. Cenchrus americanus (L.) 
Morrone] landrace varieties, 54 landrace-derived improved open-pollinated varieties and two checks (Online Resource 1). The original landrace varieties (marked with L) had been assembled during the joint pearl millet collection missions involving the "Institut de la Recherche pour le Développement" (IRD) and International Crops Research Institute for the SemiArid Tropics (ICRISAT) in 1976 and 2003, and were obtained by ICRISAT Niger in 2005 from IRD Montpellier. The improved (breeders') varieties (B) had been developed by ICRISAT and partner National programs in Nigeria, Niger, Burkina Faso, Mali and Senegal from local landraces. Five of the improved varieties (termed B_PPB) were derived from a farmer-participatory population improvement program in Niger. The 102 entries were evaluated in a pot experiment for early growth parameters, and in subsequent independent field trials to assess yield and flowering time under low-P ( $-\mathrm{P}$; without $\mathrm{P}$ fertilization) and high-P $(+\mathrm{P}$; with $\mathrm{P}$ fertilization) conditions. Since we are dealing with openpollinated varieties which are heterozygous and heterogenous, each individual within a variety is assumed to be different from the rest. We would therefore like to clarify that the term 'genotype' is only used in this case for simplicity under the assumption that 'genotype' = 'variety'. This assumption has been made throughout the text where 'genotype' is used to refer to the tested 'varieties'.

\section{Pot experimental conditions}

The pot experiment was carried out for 37 days between June and August 2011 at the ICRISAT Sahelian Centre, Sadoré in Niger (Beggi et al. 2014a). Pots with a diameter of $23 \mathrm{~cm}$ were pre-laid with $500 \mathrm{~g}$ of gravel to facilitate drainage and then filled with $8 \mathrm{~kg}$ soil obtained from a low-P field at Sadoré where field trials were also conducted. The initial soil properties included $\mathrm{pH}-\mathrm{H}_{2} \mathrm{O}$ $=5.7,3.3 \mathrm{mg}$ Bray-1-P kg ${ }^{-1}$ soil, $0.3 \%$ organic carbon and $207 \mathrm{mg}$ total $\mathrm{N} \mathrm{kg}^{-1}$ soil. The $\mathrm{P}$ treatment was imposed by basal application of $0.4 \mathrm{~g} \mathrm{P} \mathrm{pot}^{-1}$ as $2 \mathrm{~g}$ of diammonium phosphate (DAP 18-46-0) to the +P treatment and balancing the $\mathrm{N}$ in the DAP for the $-\mathrm{P}$ treatment by the addition of $0.78 \mathrm{~g}$ of urea pot $^{-1}$ to the $-\mathrm{P}$ treatment. The experimental layout was a randomized complete block design with five replicates. Pots under $-\mathrm{P}$ and $+\mathrm{P}$ were kept separately to avoid possible shading effects due to different growth rates under $-\mathrm{P}$ and + P. All plant stands were thinned to three per pot 10 days after sowing and pots were watered each 2 days to field capacity to avoid water limitation during the evaluation period. Data collected include: seedling vigor (SV) measured on a scale of $1-5(1=$ poor, $5=$ excellent $)$; height (measured by stretching the longest leaf of the most vigorous stem per pot) at 2 and 4 weeks after sowing (HT2; HT4); and shoot and root dry matter (SDM and RDM), determined by sun drying shoot and root biomass to constant weight. Root to shoot ratio (RS) was derived from these. Relative shoot growth under $-\mathrm{P}$ pot conditions (RSG) was estimated as the ratio between shoot dry matter under $-\mathrm{P}$ and $+\mathrm{P}$. Shoot $\mathrm{P}$ concentration was determined using Near Infra-Red Spectroscopy (NIRS) analysis and estimates of P acquisition (PAE) and P utilization efficiency (PUE) were calculated from these data as shown in Table 1.

\section{Field experimental conditions}

Field trials for grain yield performance under variable soil $\mathrm{P}$ conditions were conducted in four locations in West Africa: Sadoré, Niger (17 36' 28.04" N; $844^{\prime} 53.99^{\prime \prime}$ W); Gampela, Burkina Faso (12 25' 51" N; $122^{\prime} 18^{\prime \prime}$ W); Bambey, Senegal (14 42' 2.66" N, 16 27' 32.8" W); and Koporo, Mali (14 3' 49.9" N; 3 4' 31" W) during the rainy season (RS) 2010 and RS 2011. Initial soil testing revealed that soil $\mathrm{pH}-\mathrm{H}_{2} \mathrm{O}$ ranged from 4.6 to 6.5 , Bray1-P ranged from 3.0 to $7.5 \mathrm{mg} \mathrm{P} \mathrm{kg}^{-1}$ soil while total rainfall ranged from 308 to $893 \mathrm{~mm}$ per year across locations and years. The summary of the environmental conditions as well as fertilization of the trials is shown in Online Resource 2. The 102 entries were evaluated in + $\mathrm{P}$ and $-\mathrm{P}$ trials planted side by side using $17 \times 6 \alpha$-lattice design with four replications in each treatment (P-level). The total plot size was $7.2 \mathrm{~m}^{2}$ composed of two-row plots of 7 hills per row with $0.8 \mathrm{~m}$ intra- and $0.75 \mathrm{~m}$ inter-row spacing. Border rows were used on each side of the trial to avoid border effects. Only fields with initial Bray-1-P $\leq 7 \mathrm{mg} \mathrm{P} \mathrm{kg}{ }^{-1}$ soil were selected for the study. Due to unavailability of pure $\mathrm{K}$ fertilizer to balance the $\mathrm{K}$ in the $-\mathrm{P}$ treatment if NPK fertilizers were used in the $+\mathrm{P}$ treatment, only $\mathrm{P}$ and $\mathrm{N}$ were supplied using fertilizers in the current study. The $+\mathrm{P}$ treatment received $20 \mathrm{~kg} \mathrm{ha}^{-1} \mathrm{P}$ and $18 \mathrm{~kg} \mathrm{ha}^{-1} \mathrm{~N}$ at sowing in the form of diammonium phosphate (DAP), whereas the $-\mathrm{P}$ treatment received a basal application $18 \mathrm{~kg} \mathrm{ha}^{-1} \mathrm{~N}$ in the form of urea. Both treatments were then supplied with two topdressings ( 30 and 45 days after sowing) each with $16 \mathrm{~kg} \mathrm{ha}^{-1} \mathrm{~N}$ in the form of urea. Although the 
Table 1 Descriptions, method of calculation and units for trait abbreviations used in the pearl millet selection experiment at ICRISAT Sahelian Centre, Sadoré, Niger

\begin{tabular}{|c|c|c|c|}
\hline Abbreviation & Description & Calculation & Unit \\
\hline SV & Seedling vigor & & $1-5$ scale \\
\hline HT2 & Height at 2 weeks & & $\mathrm{cm}$ \\
\hline HT4 & Height at 4 weeks & & $\mathrm{cm}$ \\
\hline RDM & Root dry matter & & $\mathrm{g}$ \\
\hline SDM & Shoot dry matter & & $\mathrm{g}$ \\
\hline RS & Root to shoot ratio & RDM/SDM & \\
\hline SPC & Shoot $\mathrm{P}$ concentration & & $\mathrm{mg} \mathrm{g}^{-1}$ \\
\hline PS & Total P in shoots & $\mathrm{SDM} * \mathrm{SPC}$ & $\operatorname{mg} \mathrm{P} \operatorname{pot}^{-1}$ \\
\hline PAE & P uptake efficiency & $\mathrm{PS} / \mathrm{RDM}$ & $\mathrm{mg} \mathrm{P} \mathrm{g}^{-1}$ root \\
\hline PUE & P utilization efficiency & $\mathrm{SDM} / \mathrm{PS}$ & $\mathrm{g} \mathrm{mg}^{-1} \mathrm{P}$ \\
\hline RSG & Relative shoot growth under $-\mathrm{P}$ & $\mathrm{SDM}_{-\mathrm{P}} / \mathrm{SDM}_{+\mathrm{P}}$ & $\%$ \\
\hline $\mathrm{FLO}^{\mathrm{a}}$ & Days to flowering & & days \\
\hline $\mathrm{FD}^{\mathrm{a}}$ & Flowering delay & & days \\
\hline $\mathrm{GY}^{\mathrm{a}}$ & Grain yield & & $\mathrm{g} \mathrm{m}^{-2}$ \\
\hline $\mathrm{RYR}^{\mathrm{a}}$ & Relative yield reduction & & $\%$ \\
\hline $\mathrm{RGY}^{\mathrm{a}}$ & Residual grain yield under $-\mathrm{P}$ & & $\mathrm{g} \mathrm{m}^{-2}$ \\
\hline $\mathrm{EGY}^{\mathrm{a}}$ & Estimated grain yield & & $\mathrm{g} \mathrm{m}^{-2}$ \\
\hline
\end{tabular}

$\mathrm{P}$ treatment was recommended to be applied at sowing, the fertilization was actually based on moisture availability in the soil (to avoid burning of the seedlings) and was sometimes delayed by up to 2 weeks after sowing due to the erratic nature of rainfall within the region. The trials were conducted under rain-fed conditions. Data collected includes days from sowing to flowering (FLO) measured as the number of days from sowing to full female stigma emergence on $50 \%$ of main panicles, and grain yield $(\mathrm{GY})$ measured in $\mathrm{g} \mathrm{m}^{-2}$. To calculate harvest index (HI), stover weight (SWT) and panicle weight (PWT) were also measured in $\mathrm{g} \mathrm{m}^{-2}$ and $\mathrm{HI}$ was calculated as GY/(SWT+PWT). Assuming that border effects at the respective ends of each plot are the same for all entries, the whole plots including the first and last plant of each row were harvested and included in the calculation of grain yield.

\section{Data analysis}

Single trial analysis (trial $=$ P-level at one location in 1 year) was carried out for both pot and field experiments using REML linear mixed models in GENSTAT 17th edition. For the pot experiment, both genotypes and replications were considered random while for the field experiments, genotypes, replications as well as blocks nested in replications were considered random.
To be able to identify which environments to include in generating best linear unbiased predictors (BLUPs; estimated population means when genotypes are used as random effects, which give an indication of genotypic stability in performance over a range of environments), the grain yields from single trials were used to visualize the genotype and environmental relationship graphically using a genotype and genotype by environment (GGE) main effect biplot. Only environments which ranked genotypes in a similar manner were used in combined analysis while environments which formed a different mega-environment (ranked genotypes in a relatively different way) were left out. To further delineate our environments since the GGE biplot was found to explain only about $56 \%$ of the observed variation, the BLUPs generated from initial combined analysis across the remaining environments which appeared to rank genotypes in a similar manner as shown in the GGE biplot were subjected to a multiple linear regression analysis with single trial means. Only single trials with significant effects in the multiple linear regression models were eventually used in generating BLUPs used for further analysis. Since only a few locations had data for both years, we did not separate location and year effects rather each location-year combination was considered an independent environment. Combined analysis (generating BLUPs) within one P-level was done by 
considering genotypes, environments and interactions, replications nested in environments and blocks nested in replications as random. Across treatments (P-levels) and environments (location-year combinations), the P-level was considered as fixed whereas genotypes, environments and all interactions, replications nested in environments and blocks nested in replications were all considered random. Data were transformed if residuals were not normally distributed. We had to drop Koporo 2010 and Sadore 2011 trials for lack of proper trial establishment due to drought immediately after sowing leading to too many missing data that could not be corrected for by the standardized average variance of a difference.

The extent of error per trial was then calculated according to Leiser et al. (2012) as:

$a V D=(\sqrt{V D} \div \mu) \times 100$

where VD is the average variance of a difference between means of genotypes, and $\mu$ is the trial mean.

The genetic coefficients of variation $\left(\mathrm{CV}_{\mathrm{g}}\right)$ were calculated as:

$C V g=\left(\sqrt{\sigma_{g}^{2}} \div \mu\right) \times 100$

where $\sigma_{g}^{2}$ is the genetic variance component and $\mu$ the population mean. This allows for comparison of genetic variance components across trials with different means. To estimate the precision of the trials, repeatability estimate $\left(w^{2}\right.$; equivalent of broad-sense heritability in multiple trials) for each single trial was calculated according to Piepho and Möhring (2007) as:

$w^{2}=\sigma_{g}^{2} \div\left\{\sigma_{g}^{2}+(V D / 2)\right\}$

where VD is the average variance of a difference between means of genotypes and $\sigma_{\mathrm{g}}^{2}$ is the genetic variance component. Relative yield reduction (RYR, \%) in $-\mathrm{P}$ versus $+\mathrm{P}$ treatment was calculated according to Venuprasad et al. (2007) as:

$R Y R=\left\{1-\left(\mu_{-P} / \mu_{+P}\right)\right\} \times 100$

where $\mu_{-\mathrm{P}}$ is the mean under $-\mathrm{P}$ and $\mu_{+\mathrm{P}}$ is the mean under $+\mathrm{P}$. Broad-sense heritability was calculated in combined analysis according to Cullis et al. (2006) as:

$h^{2}=1-\left(P E V / 2 \sigma_{g}^{2}\right)$ where, $\mathrm{PEV}$ is the predicted error variance of genotypic effects while $\sigma_{\mathrm{g}}^{2}$ is the genotypic variance. Genetic correlation between $-\mathrm{P}$ and $+\mathrm{P}$ performance was calculated according to Cooper et al. (1996) as:

$r_{g(-P,+P)}=r_{p(-P,+P)} /\left(h_{-P} \times h_{+P}\right)$

where $r_{g}$ is the genetic correlation, $r_{p}$ is the correlation coefficient between predicted means of the genotypes, while $h_{-p}$ and $h_{+p}$ are the respective square roots of broad-sense heritability (or repeatability estimates for single trial analysis) under $-\mathrm{P}$ and $+\mathrm{P}$.

Since $\mathrm{P}$ stress is known to induce delay in flowering, flowering delay under $-\mathrm{P}$ was calculated as:

$F D=F L O_{-P}-F L O_{+P}$

Due to non-significant genotype by P-level interaction and a high linear relationship between $-\mathrm{P}$ and $+\mathrm{P}$ grain yield $\left(\mathrm{R}^{2}=0.64\right)$, genotypic residual grain yields obtained as the difference between the observed GY under $-\mathrm{P}$ and the estimated $\mathrm{GY}$ for $-\mathrm{P}$ from a linear regression between $-\mathrm{P}$ and $+\mathrm{P}$ yields were used as proxy for genotypic $\mathrm{P}$ efficiency under field conditions (Beggi et al. 2014b). According to Vadez et al. (2007), the residual would then represent the part of GY variation under $-\mathrm{P}$ that is not explained by yield potential.

Residual grain yield under $-\mathrm{P}$ (RGY) was therefore calculated as:

$R G Y=B L U P_{-p}-\left(\alpha+\beta B L U P_{+p}\right)$

where BLUP $_{-P}$ is the predicted grain yield across four environments under $-\mathrm{P}, \mathrm{BLUP}_{+\mathrm{P}}$ is the predicted grain yield across four environments under $+\mathrm{P}, \alpha$ and $\beta$ are the intercept and the slope, respectively, of the linear regression between BLUP $_{-\mathrm{P}}$ and $\mathrm{BLUP}_{+\mathrm{P}}$

For single environment means, we examined the relationships among mean FD, mean RYR and total rainfall amount (RF). The relationship between genotypic FLO (used as an estimate for maturity), RGY and GY was determined using Pearson's correlation coefficients. Since FLO, FD, and RGY appeared to be the main contributors to GY performance under $-\mathrm{P}$, we sought to establish the amount of variation under $-\mathrm{P}$ explained by these three traits. Due to high correlation between FLO and HI, HI index was not included in the additive model as the two traits confounded each other and based on the fact that $\mathrm{HI}$ is not quite independent of GY, FLO was considered a better adaptation trait. 
Estimated grain yield (EGY) was obtained as an additive function of FLO, FD under -P and RGY (RYR was not included due to its high correlation with RGY) using multiple linear regression analysis (Vadez et al. 2013).

Estimated grain yield under $-\mathrm{P}$ was therefore calculated as:

$E G Y=\alpha+\beta_{1} F L O+\beta_{2} F D+\beta_{3} R G Y$

where $\alpha$ is the intercept (was found to be 165 in the current study), $\beta 1$ (-1.68), $\beta 2$ (1.85), $\beta 3$ (0.84) are the slopes of the respective traits based on BLUPs under the current study shown in brackets. Since grain yield is our primary trait, all further analyses were done using genotypes ranked based on BLUPs and supported by single environment means. However, because we also estimated P-efficiency based on RGY, we sought to compare genotypes ranked based on RGY with genotypic ranks for BLUPs, FLO, FD and RYR.

To examine the relationship between tolerant and susceptible genotypes, the means of various early $\mathrm{P}$ efficiency traits measured under pot conditions including SV, SPC, PS, PAE, PUE as well as P efficiencyrelated traits measured under field conditions (FLO, FD, HI, RYR, RGY, EGY and BLUP) were compared between the tolerant and susceptible groups. Tolerant and susceptible genotypes had been selected based on BLUPs under $-\mathrm{P}$ by selecting the best $10 \%$ genotypes as tolerant and the worst $10 \%$ genotypes as susceptible. We also examined the differences in means for the same traits between landraces and improved open-pollinated varieties under the current study. Differences between means were tested using a two-sided $t$-test assuming unequal variances between the two groups. To back up the findings from these BLUP obtained relationships, we also compared FLO, FD, RYR, RGY, GY and EGY between tolerant and susceptible individuals selected based on actual GY under -P for each single environment and also between landraces and improved openpollinated varieties.

To be able to establish whether directly selecting pearl millet under $-\mathrm{P}$ field conditions was the better strategy or indirectly selecting for performance under $-\mathrm{P}$ in $+\mathrm{P}$ conditions or using early growth $\mathrm{P}$ efficiency traits was the most efficient way, response to direct selection under $-\mathrm{P}$ was calculated according to Falconer (1989) as:

$R=i h \sigma_{g}$ where $i$ is the selection intensity, $h$ is the square root of the broad-sense heritability and $\sigma_{\mathrm{g}}$ the square root of the genetic variance component of grain yield best linear unbiased predictor (BLUP) under $-\mathrm{P}$ conditions. Potential secondary traits for indirect selection for grain yield targeting $-\mathrm{P}$ environments were evaluated by calculating their correlated response to selection according to Falconer (1989) as:

$C R=i_{y} \times h_{y} \times r_{g(x y)} \times \sigma_{g(x)}$

where $i_{(y)}$ is the selection intensity for the indirect trait, $\mathrm{h}_{(\mathrm{y})}$ is the square root of the broad-sense heritability (repeatability estimate for traits measured in pots) of the indirect trait, $r_{g(x y)}$ is the genetic correlation between the indirect trait and grain yield BLUP under $-\mathrm{P}$ and $\sigma_{\mathrm{g}(\mathrm{x})}$ is the square root of the variance component of grain yield BLUP under $-\mathrm{P}$. Identical selection intensities at $10 \%$ selection differential were assumed for $-\mathrm{P}$ and $+\mathrm{P}$ under both pot and field conditions $(i=1.755$ for $10 \%$ selected fraction; Wricke and Weber 1986). We also calculated selection differentials (S) at $10 \%$ based on BLUPs under $-\mathrm{P}$ and $+\mathrm{P}$ as:

$S=\mu_{s}-\mu_{g}$

where $\mu_{\mathrm{s}}$ is the mean of the selected fraction, and $\mu_{\mathrm{g}}$ is the population mean.

\section{Results}

Genotypic variation and performance under low soil phosphorus in pot conditions

All trait means were reduced under $-\mathrm{P}$ as compared to + $\mathrm{P}$ except for RS and PUE which increased under $-\mathrm{P}$ instead (Table 2). At 4 weeks after sowing, plants were already almost $30 \mathrm{~cm}$ taller under $+\mathrm{P}$ than $-\mathrm{P}$. Both $\mathrm{RDM}$ and SDM were almost three times higher under $+\mathrm{P}$ than $-\mathrm{P}($ Mean $=7.9$ and $10.3 \mathrm{~g}$ under $-\mathrm{P}$ and 20.8 and $31.4 \mathrm{~g}$ under $+\mathrm{P}$ for the respective traits), PS was more than ten times higher under $+\mathrm{P}$ than $-\mathrm{P}($ Mean $=$ 17.9 and $202.4 \mathrm{mg}$ for $-\mathrm{P}$ and $+\mathrm{P}$, respectively) whereas $\mathrm{PAE}$ was about four times higher under $+\mathrm{P}(2.5 \mathrm{mg} \mathrm{P}$ $\mathrm{g}^{-1}$ root under $-\mathrm{P}$ and $10.4 \mathrm{mg} \mathrm{P} \mathrm{g}^{-1}$ root under $+\mathrm{P}$; Table 2). On the other hand, RS was about 1.5 times higher under $-\mathrm{P}$ than $+\mathrm{P}($ mean $=0.8$ and 0.6 for $-\mathrm{P}$ and $+\mathrm{P}$ respectively) whereas $\mathrm{PUE}$ was three times higher under $-\mathrm{P}$ than $+\mathrm{P}($ mean $=0.6$ and 0.2 for $-\mathrm{P}$ and $+\mathrm{P}$ 
Table 2 Predicted means, repeatability estimates $\left(w^{2}\right)$, coefficients of genetic variation $\left(\mathrm{CV}_{\mathrm{g}}\right)$ and estimated extend of error $(\mathrm{aVD})$ under $-\mathrm{P}$ and $+\mathrm{P}$, the genotypic variance component combined across $P$ levels $(G)$ and genotype by P-level interaction $(G x$
P) of traits measured on 102 pearl millet landraces and improved open-pollinated varieties in a pot experiment at Sadoré, Niger under $-\mathrm{P}$ and $+\mathrm{P}$ conditions

\begin{tabular}{|c|c|c|c|c|c|c|c|c|c|c|c|}
\hline \multirow[t]{2}{*}{ Trait $^{\mathrm{a}}$} & \multicolumn{4}{|l|}{$-\mathrm{P}$} & \multicolumn{4}{|l|}{$+\mathrm{P}$} & \multicolumn{3}{|l|}{ Combined } \\
\hline & Mean & $w^{2}$ & $\mathrm{CV}_{\mathrm{g}}$ & $\mathrm{aVD}$ & Mean & $w^{2}$ & $\mathrm{CV}_{\mathrm{g}}$ & aVD & $\mathrm{G}^{\mathrm{b}}$ & $\mathrm{P}^{\mathrm{b}}$ & $G \times P^{b}$ \\
\hline SV & 2.9 & 0.58 & 7.6 & 9 & 3.7 & 0.63 & 7.2 & 7.8 & $4.43 * * *$ & $* * *$ & $1.35 * * *$ \\
\hline HT2 & 16.4 & 0.62 & 9.7 & 10.7 & 31.2 & 0.69 & 4.4 & 4.2 & $213.4 * * *$ & $* * *$ & $56.9^{* *}$ \\
\hline HT4 & 50.6 & 0.63 & 6.3 & 6.8 & 76.5 & 0.74 & 5.6 & 4.7 & $312 * * *$ & $* * *$ & $89.2 * *$ \\
\hline RDM & 7.9 & 0.77 & 24.3 & 18.9 & 20.8 & 0.86 & 21.4 & 12.1 & $11.53 * * *$ & $* * *$ & $5.34 * * *$ \\
\hline SDM & 10.3 & 0.78 & 17.9 & 13.4 & 31.4 & 0.79 & 7.8 & 5.6 & $3.36 * * *$ & $* * *$ & $1.13 * * *$ \\
\hline $\mathrm{RS}$ & 0.8 & 0.75 & 21.0 & 17.4 & 0.6 & 0.79 & 19.2 & 14.1 & $0.012 * * *$ & $* * *$ & $0.009 * * *$ \\
\hline SPC & 1.7 & 0.78 & 29.1 & 22.1 & 6.7 & 0.63 & 6.6 & 7.1 & $0.21 * * *$ & $* * *$ & $0.08 * * *$ \\
\hline PS & 17.9 & 0.93 & 88.1 & 33.5 & 202.4 & 0.95 & 11.9 & 4.0 & $513.1 * * *$ & $* * *$ & $116.9 * * *$ \\
\hline PAE & 2.5 & 0.84 & 49.4 & 28.7 & 10.4 & 0.61 & 24.8 & 21.7 & $2.24 * * *$ & $* * *$ & $0.36^{* * *}$ \\
\hline PUE & 0.6 & 0.72 & 22.0 & 19.4 & 0.2 & 0.80 & 11.7 & 8.2 & $0.009 * * *$ & $* * *$ & $0.002 * * *$ \\
\hline RSG & 0.3 & 0.68 & 11.5 & 11.1 & & & & & & & \\
\hline
\end{tabular}

${ }^{\mathrm{a}}$ Trait abbreviations shown in Table $1,{ }^{\mathrm{b}} * * *=$ significant at $p<0.001$

respectively; Table 2). Repeatability estimates were numerically lower under $-\mathrm{P}$ in most cases, ranging from 0.58 to 0.93 under $-\mathrm{P}$ and 0.63 to 0.95 under $+\mathrm{P}$. Coefficients of genetic variation among the tested varieties were generally higher under $-\mathrm{P}$ but were equally accompanied with a higher extend of error. Under $-\mathrm{P}$, PS had the highest coefficient of genetic variation. Across P levels, the P-level treatment main effect, the genotypic and genotype by P-level interaction effects were significant $(p<0.001)$ for all traits reported (Table 2).

Genetic variation and grain yield performance under low soil phosphorus in field conditions

Grain yields (GY) were generally reduced under $-\mathrm{P}$ across all locations (Table 3). Predicted means for every variety (hereby referred to as 'genotype') in each of the six environments (site-year combinations) and BLUPs calculated across the four environments in which the genotypes were ranked in a similar manner (formed one mega-environment) are presented in Online Resource 1 for both $-\mathrm{P}$ and $+\mathrm{P}$ treatments. GY means ranged from 38.7 to $150.1 \mathrm{~g} \mathrm{~m}^{-2}$ under $-\mathrm{P}$ and 67.3 to $188.0 \mathrm{~g} \mathrm{~m}^{-2}$ under $+\mathrm{P}$ (Table 3$)$. Repeatability estimates ranged from 0.61 to 0.85 under $-\mathrm{P}$ and from 0.70 to 0.91 under $+\mathrm{P}$ (Table 3). Except for one location which had relative yield reduction (RYR) of $58.5 \%$, RYR was less than
$30 \%$ in most locations. Genetic correlation between performance under $-\mathrm{P}$ and $+\mathrm{P}$ ranged from 0.63 to 0.91 (Table 3). Mean FD under $-\mathrm{P}$ ranged from 0.14 to 2.25 days whereas total RF ranged from 308 to $893 \mathrm{~mm}$ across environments (Table 3 ). The correlation between FD and RF was significant and negative ( $r=-$ $\left.0.68^{* * *}\right)$ and higher FD was in turn positively associated with higher RYR ( $r=0.47^{* *}$; for correlated values, see Table 3$)$. In the GGE biplot which explained around $56 \%$ of the observed variation, the environments were differentiated into four sectors although most of the environments fell in the same sector (Online Resource 3). Only the highest yielding environment, Bambey in 2010 for both $-\mathrm{P}$ and $+\mathrm{P}$, separated clearly from the other site-season combinations and seemed to belong to a different mega-environment (i.e. the best performing entries differed between Bambey 2010 and the other site-season combinations). The differences between $-\mathrm{P}$ and $+\mathrm{P}$ treatments were not very large across locations as can be visualized by the narrow angles between $-\mathrm{P}$ and $+\mathrm{P}$ treatment for each location (Online Resource 3). Since Bambey 2010 was uniquely separated into a different mega environment, we did not include it in the combined analysis for generating BLUPs. Multiple linear regression of the BLUPs generated based on the five remaining environments on their single environment means showed that Gampela 2011 did not contribute to the additive model either and was also omitted. 
Table 3 Grain yield means $\left(\mu ; \mathrm{g} \mathrm{m}^{-2}\right)$, repeatability estimate $\left(w^{2}\right)$, coefficients of genetic variation $(\mathrm{CVg})$, and the estimated extend of error (aVD) under low phosphorus $(-\mathrm{P})$ and high phosphorus $(+\mathrm{P})$, the relative yield reduction under $-\mathrm{P}(\mathrm{RYR}, \%)$, the genetic correlation $\left(\mathrm{r}_{\mathrm{g}}\right)$ between $-\mathrm{P}$ and $+\mathrm{P}$, flowering delay under $-\mathrm{P}$ (FD, d) and rainfall per location (RF, mm) as measured on 102 pearl millet landrace and improved open-pollinated varieties in six environments (site-season combinations) of West Africa

\begin{tabular}{|c|c|c|c|c|c|c|c|c|c|c|}
\hline Year & Location & Treatment & $\mu$ & $w^{2}$ & $\mathrm{CVg}$ & $\mathrm{aVD}$ & RYR & $r_{g}$ & FD & $\mathrm{RF}$ \\
\hline \multirow[t]{6}{*}{2010} & \multirow[t]{2}{*}{ Gampela } & $-\mathrm{P}$ & 38.7 & 0.61 & 10.8 & 12.2 & \multirow[t]{2}{*}{58.5} & \multirow[t]{2}{*}{0.77} & \multirow[t]{2}{*}{1.45} & \multirow[t]{2}{*}{822.9} \\
\hline & & $+\mathrm{P}$ & 93.2 & 0.70 & 19.1 & 17.7 & & & & \\
\hline & \multirow[t]{2}{*}{ Sadore } & $-\mathrm{P}$ & 55.2 & 0.85 & 38.3 & 22.8 & \multirow[t]{2}{*}{27.9} & \multirow[t]{2}{*}{0.82} & \multirow[t]{2}{*}{2.22} & \multirow[t]{2}{*}{646.0} \\
\hline & & $+\mathrm{P}$ & 76.6 & 0.87 & 41.7 & 22.4 & & & & \\
\hline & \multirow[t]{2}{*}{ Bambey } & $-\mathrm{P}$ & 150.1 & 0.80 & 20.9 & 14.8 & \multirow[t]{2}{*}{20.2} & \multirow[t]{2}{*}{0.78} & \multirow[t]{2}{*}{1.82} & \multirow[t]{2}{*}{601.4} \\
\hline & & $+\mathrm{P}$ & 188.0 & 0.77 & 18.6 & 14.3 & & & & \\
\hline \multirow[t]{8}{*}{2011} & \multirow[t]{2}{*}{ Gampela } & $-\mathrm{P}$ & 109.0 & 0.52 & 12.0 & 11.0 & \multirow[t]{2}{*}{7.3} & \multirow[t]{2}{*}{0.83} & \multirow[t]{2}{*}{0.14} & \multirow[t]{2}{*}{893.0} \\
\hline & & $+\mathrm{P}$ & 117.6 & 0.58 & 24.2 & 23.6 & & & & \\
\hline & \multirow[t]{2}{*}{ Koporo } & $-\mathrm{P}$ & 80.7 & 0.66 & 12.3 & 12.4 & \multirow[t]{2}{*}{29.2} & \multirow[t]{2}{*}{0.63} & \multirow[t]{2}{*}{2.25} & \multirow[t]{2}{*}{308.0} \\
\hline & & $+\mathrm{P}$ & 114.1 & 0.91 & 30.5 & 13.6 & & & & \\
\hline & \multirow[t]{4}{*}{ Bambey } & $-\mathrm{P}$ & 67.3 & 0.78 & 39.0 & 29.3 & \multirow[t]{4}{*}{7.8} & \multirow[t]{4}{*}{0.91} & \multirow[t]{4}{*}{0.93} & \multirow[t]{4}{*}{584.0} \\
\hline & & $+\mathrm{P}$ & 73.0 & 0.78 & 38.0 & 28.4 & & & & \\
\hline & & Mean -P & 83.5 & 0.70 & 22.2 & 17.1 & & & & \\
\hline & & Mean $+\mathrm{P}$ & 110.4 & 0.77 & 28.7 & 20 & & & & \\
\hline
\end{tabular}

Consequently, BLUPs were estimated for the remaining four environments which were more representative of each other (similar) and used for further analysis. The broad-sense heritability of BLUPs was 0.73 under $-\mathrm{P}$ and 0.77 under $+\mathrm{P}$ conditions (Table 4 ). In the combined

Table 4 Variance components ( \pm se) for various sources under $-\mathrm{P}$, combined, and $+\mathrm{P}$ conditions, broad-sense heritability $\left(\mathrm{h}^{2}\right)$ and means $(\mu)$ generated from a combined analysis of grain yield of 102 pearl millet landraces and improved open-pollinated varieties across four environments of West Africa

\begin{tabular}{llll}
\hline & $-\mathrm{P}$ & Combined & $+\mathrm{P}$ \\
\hline$\sigma_{\mathrm{G}}^{2} \pm \mathrm{se}$ & $0.68 \pm 0.2 * * *$ & & $0.94 \pm 0.2 * * *$ \\
$\sigma_{\mathrm{G} \times \mathrm{E}} \pm \mathrm{se}$ & $1.16 \pm 0.2 * * *$ & & $1.66 \pm 0.22 * * *$ \\
$\mathrm{~h}^{2}$ & 0.73 & & 0.77 \\
$\mu$ & 57.7 & & 82.0 \\
$\sigma_{\mathrm{G}}^{2} \pm \mathrm{se}$ & & $0.83 \pm 0.2 * * *$ & \\
$\sigma_{\mathrm{G} \times \mathrm{E}}^{2} \pm \mathrm{se}$ & & $1.25 \pm 0.2 * * *$ & \\
$\sigma_{\mathrm{G} \times \mathrm{P}} \pm \mathrm{Se}$ & & $0.014 \pm 0.02$ & \\
$\sigma_{\mathrm{G} \times \mathrm{E} \times \mathrm{P}}^{2} \mathrm{se}$ & & $0.021 \pm 0.1$ & \\
$\mathrm{~h}^{2}$ & & 0.85 & \\
$\mu$ & & 69.4 &
\end{tabular}

${ }^{\text {a }}$ Components refer to transformed grain yield values due to residuals not being normal

${ }^{\mathrm{b}} G$ Genotype, $E$ Environment, $P$ P-level, $x$ Interaction, se Standard error analysis across environments, both the genotypic $(\mathrm{G})$ and genotype by environment ( $\mathrm{G} \times \mathrm{E}$ ) interaction variances were significant $(p<0.001)$ although $\mathrm{G} \times \mathrm{E}$ variance component was larger as compared to the $G$ variance component for each P-level separately. Across Plevels, the $\mathrm{G}$ and the $\mathrm{G} \times \mathrm{E}$ variance components were also significant $(p<0.001)$, the P-level main effect was significant $(p<0.05)$ but the interaction between genotypes and P-level (G x P) and the three-way interaction between genotypes, P-levels and environments ( $\mathrm{G}$ x P x E) were both not significant (Table 4).

Phosphorus efficiency between groups of varieties under $-\mathrm{P}$ conditions

Generally, high yielding genotypes flowered early under both $-\mathrm{P}$ and $+\mathrm{P}$ conditions (Fig. 1). The relationship between FLO and GY was $r=-0.63 * * *$ for $-\mathrm{P}$ and $0.62 * * *$ for $+\mathrm{P}$ treatments (Fig. 1). Genotypic FLO under $-\mathrm{P}$ ranged from 55.7 to 76.8 days, FD ranged from -0.85 to 4.2 days, HI ranged from 10 to $30 \%$, RYR ranged from -5.4 to $46.8 \%$ whereas RGY under $-\mathrm{P}$ ranged from -14.6 to $21.0 \mathrm{~g} \mathrm{~m}^{-2}$ (Online Resource 1). Genotypic RGY was weakly negatively correlated with FLO ( $r=$ $\left.-0.25^{*}\right)$ and not significantly correlated with FD $(r=-0.15)$, highly negatively correlated with RYR 


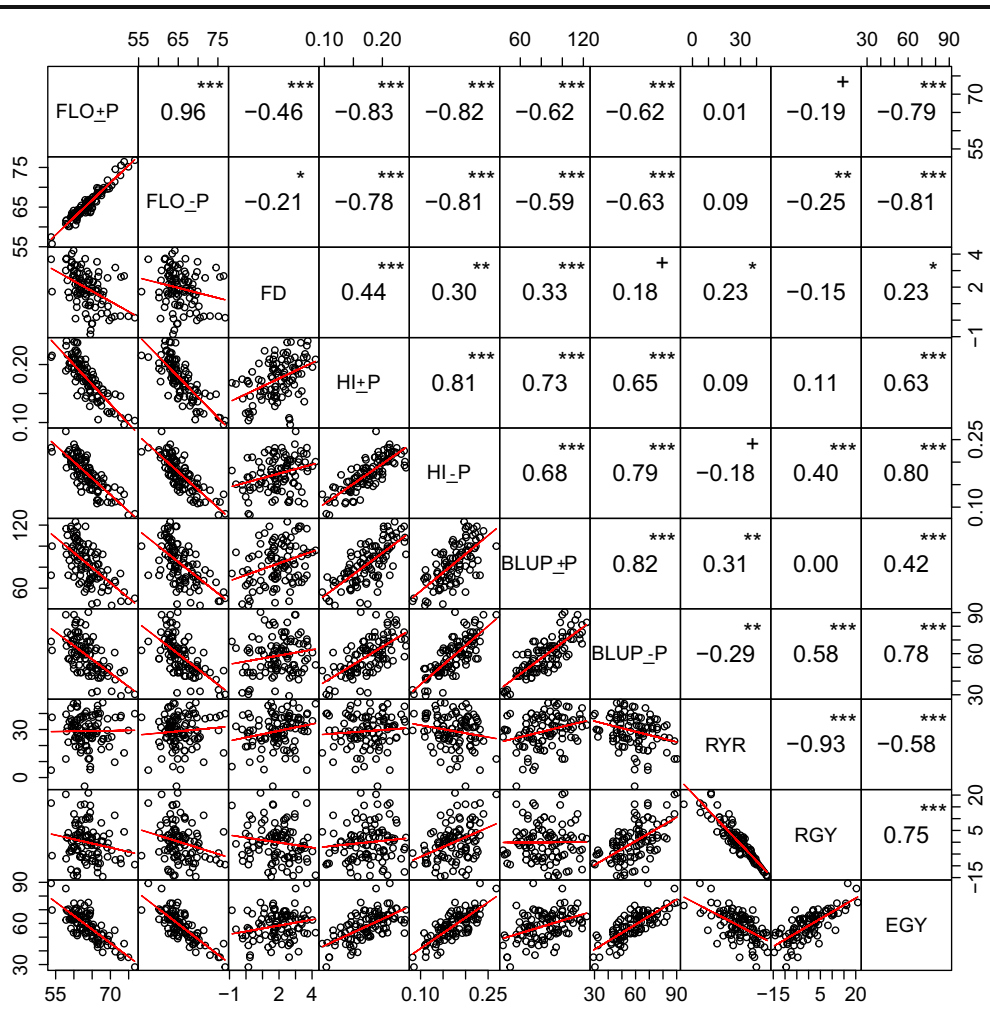

Fig. 1 Genotypic correlations among flowering time under $+\mathrm{P}$ $(\mathrm{FLO}+\mathrm{P})$, under $-\mathrm{P}\left(\mathrm{FLO}_{-}-\mathrm{P}\right)$, flowering delay under $-\mathrm{P}(\mathrm{FD})$, harvest index under $+\mathrm{P}\left(\mathrm{HI}_{-}+\mathrm{P}\right)$, under $-\mathrm{P}\left(\mathrm{HI}_{-}-\mathrm{P}\right)$, best linear unbiased predictors under $+\mathrm{P}^{-}\left(\mathrm{BLUP}_{-}+\mathrm{P}\right)$, under $-\mathrm{P}\left(\mathrm{BLUP}_{-}-\mathrm{P}\right)$, relative yield reduction under $-\mathrm{P}(\mathrm{RYR})$, residual grain yields under $-\mathrm{P}(\mathrm{RGY})$ and estimated grain yield under $-\mathrm{P}$ (EGY) measured/ calculated from 102 open-pollinated pearl millet landrace and breeder-improved varieties analyzed across four environments of West Africa. ${ }^{\mathrm{a}}$ Trait abbreviations shown in the diagonal, ${ }^{\mathrm{b}}+,{ }^{*}, * *$, $* * *$ indicate significance at $p<0.1, p<0.05, p<0.01, p<0.001$, respectively $(r=-0.93 * * *)$ and positively correlated with BLUPs under $-\mathrm{P}$ ( $r=0.58^{* * *}$; Fig. 1). There was significant association between RGY under $-\mathrm{P}$ and $\mathrm{HI}$ under $-\mathrm{P}$ $(r=0.40 * * *)$ but not under $+\mathrm{P}(r=0.11)$. The EGY from the additive model involving FLO, FD under $-\mathrm{P}$ and RGY under $-\mathrm{P}$ was highly significantly correlated to actual BLUPs under $-\mathrm{P} \quad\left(r=0.78^{* * *}\right.$; Fig. 1). The additive model explained about $61 \%$ of the observed variation for BLUPs under $-\mathrm{P}$, $66.2 \%$ in Bambey 2010, $71.7 \%$ in Bambey 2011, $74.6 \%$ in Gampela 2010, $78.1 \%$ in Gampela 2011, $78.3 \%$ in Koporo 2011 and $69.6 \%$ of the observed variation under $-\mathrm{P}$ (data not shown). Table 5 shows the comparison of genotypic ranks for BLUPs, FLO, FD and RYR if the genotypes were selected based on RGY at $10 \%$ selection differential. Under $-\mathrm{P}$ conditions, tolerant genotypes (highest $10 \%$ BLUPs under $-\mathrm{P}$ ) had slightly lower SV and higher SPC and lower PS in early growth $\mathrm{P}$ efficiency-related traits compared to susceptible genotypes (lowest $10 \%$ BLUPs under $-\mathrm{P}$ ). There was no difference in PAE and PUE between tolerant and susceptible genotypes at early growth stage (Fig. 2a). With regard to performance under field conditions, tolerant genotypes were early flowering and usually had higher HI, lower RYR and higher RGY as compared to susceptible genotypes (Fig. 2a). No significant difference was observed for FD between tolerant and susceptible genotypes. Original landrace varieties (Landraces) and breeder-improved open-pollinated varieties (Breeders' varieties) did not differ for most traits but original landraces had higher early seedling vigor with higher PS, flowered later and had lower HI and lower BLUPs than breeder-improved open-pollinated varieties. No difference in RGY was observed for the two groups though (Fig. 2b). For single locations, tolerant genotypes flowered earlier in four of the six environments except for Bambey 2010 in which tolerant genotypes flowered later than susceptible ones 
Table 5 Best varieties (10\%) when selected based on residual grain yields (RGY) under $-\mathrm{P}$ conditions, their means and (ranks) for days to flowering (FLO) under $-\mathrm{P}$, flowering delay (FD), grain

\begin{tabular}{|c|c|c|c|c|c|c|c|}
\hline Trait & Variety & $\mathrm{FLO}_{-}-\mathrm{P}$ & FD & BLUP_-P & $\mathrm{BLUP}_{-}+\mathrm{P}$ & RYR & RGY \\
\hline \multirow[t]{10}{*}{ Residual grain yield (RGY) } & PE00077(L) & $65.2(54)$ & $0.5(81)$ & $90.2(1)$ & $102.2(18)$ & $0.7(2)$ & $27.3(1)$ \\
\hline & PE02604(L) & $61.4(7)$ & $3.0(13)$ & $88.3(3)$ & $100.0(19)$ & $6.4(7)$ & $19.8(2)$ \\
\hline & GBx92222_YLD_2009(B) & $56.9(2)$ & $2.5(27)$ & $68.8(25)$ & $72.2(68)$ & $3.2(4)$ & $16.2(3)$ \\
\hline & PE11298(L) & $65.1(52)$ & $1.7(57)$ & $59.2(53)$ & $56.2(94)$ & $-2.2(1)$ & $15.7(4)$ \\
\hline & Serkin_C2_Kandela_SMS (B_PPB) & $63.5(25)$ & $1.3(65)$ & $82.8(6)$ & $98.0(24)$ & $8.3(11)$ & $15.4(5)$ \\
\hline & Strigares_expvar_ep_court(B) & $64.0(37)$ & $-1.3(101)$ & $68.8(24)$ & $73.9(65)$ & $4.0(5)$ & $15.2(6)$ \\
\hline & Intilène(L) & $65.8(59)$ & $1.0(72)$ & $59.2(52)$ & $62.4(88)$ & $2.6(3)$ & $12.2(7)$ \\
\hline & Doga_C2_PF_comb(B-PPB) & $63.3(22)$ & $2.8(17)$ & $88.3(2)$ & $114.5(7)$ & $12.2(23)$ & $11.6(8)$ \\
\hline & PE00456(L) & $72.1(95)$ & $0.2(88)$ & $60.8(47)$ & $67.2(79)$ & $4.2(6)$ & $11.0(9)$ \\
\hline & PE02830(L) & $67.0(67)$ & $2.8(19)$ & $68.8(22)$ & $82.8(49)$ & $8.0(9)$ & $10.1(10)$ \\
\hline
\end{tabular}

yield best linear unbiased predictors (BLUPs) under $-\mathrm{P}$ and $+\mathrm{P}$, relative yield reduction (RYR) under $-\mathrm{P}$ as estimated from four environments of West Africa

\begin{abstract}
and Gampela 2011 where there was no difference in FLO between the two groups (Online Resource 4). Comparison between landrace and improved varieties in single environments also revealed that landrace varieties flowered later than improved open-pollinated varieties except for Gampela 2011 but the two groups did not differ in RGY (data not shown).
\end{abstract}

Response to direct versus indirect selection for low phosphorus field conditions

Genotypes were ranked differently for GY BLUPs in -P and $+\mathrm{P}$ conditions with a cross-over interaction observed for the best variety under $-\mathrm{P}$ and $+\mathrm{P}$ conditions and the top ten best varieties under both $-\mathrm{P}$ and $+\mathrm{P}$ conditions (Online Resource 5). Direct selection under $-\mathrm{P}$ conditions in the field gave the highest response to selection $\left(20.1 \mathrm{~g} \mathrm{~m}^{-2}\right.$ followed by indirect selection under $+\mathrm{P}$ conditions for performance under $-\mathrm{P}$ conditions (16.3 $\mathrm{g} \mathrm{m}^{-2}$; Table 6). Genetic correlation between the traits measured under pot conditions and GY under -P were very low (Table 6). Consequently, correlated response to selection based on traits measured in the pots was lower than direct selection in field trials. Correlated response to selection under pot conditions ranged from $0.2 \mathrm{~g} \mathrm{~m}^{-2}$ (selection for RS) to $6.1 \mathrm{~g} \mathrm{~m}^{-2}$ (selection for SV; Table 6). Furthermore, direct selection under $-\mathrm{P}$ had a numerically higher selection differential $\left(25.4 \mathrm{~g} \mathrm{~m}^{-2}\right)$ compared to indirect selection under $+P$ (19.4 $\mathrm{g} \mathrm{m}^{-2}$; Online Resource 6).
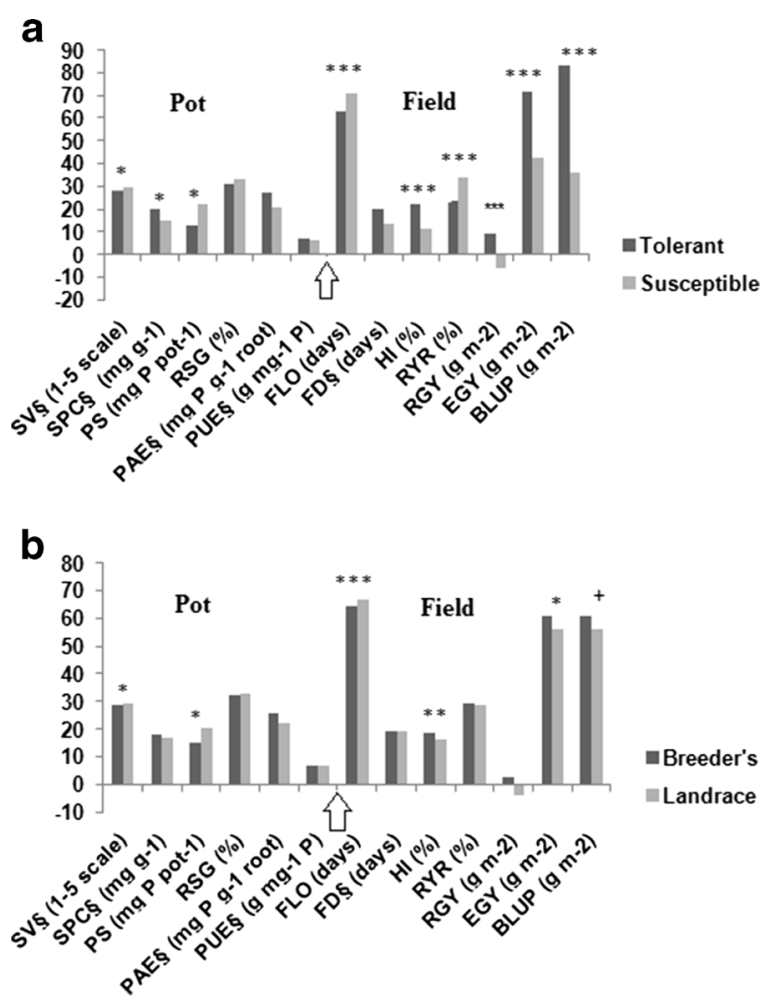

Fig. 2 Mean comparisons for various traits between tolerant (T) and susceptible (S) genotypes selected based on best linear unbiased predictors (BLUPs) as well as between performance of landraces (Landrace) and improved open-pollinated varieties (Breeder's) across four environments of West Africa. ${ }^{\text {a Trait abbre- }}$ viations are explained in Table $1,{ }^{\text {' ' }}$ ' after the trait abbreviation implies the mean $\mathrm{x} 10$ for scaling purposes, ${ }^{\mathrm{c}}$ the arrow below each figure differentiates traits measured under pot conditions (left $)$ and those measured under field conditions (right), ${ }^{\mathrm{d}}$ if indicated on the figure, $+, *, * *, * * *$ indicate significant differences between the means of the two groups for a given trait at $p<0.1, p<0.05$, $p<0.01, p<0.001$, respectively 
Table 6 Selection intensity (i), square roots of broad-sense heritability $(\mathrm{h})$, genetic correlation $\left(\mathrm{r}_{\mathrm{g}}\right)$ between various traits and BLUPs for GY of pearl millet open-pollinated varieties under low phosphorus (-P), response to direct selection (first row), correlated response (CR) to selection under high phosphorus $\left(\mathrm{GY}_{-}+\mathrm{P}\right)$ field conditions and to indirect selection for various traits measured under pot conditions

\begin{tabular}{lllll}
\hline Trait $^{\mathrm{a}}$ & $\mathrm{i}$ & $\mathrm{h}$ & $\mathrm{r}$ & $\mathrm{CR}$ \\
\hline GY_-P & 1.75 & 0.86 & & 20.1 \\
GY_+P & 1.75 & 0.88 & 0.79 & 16.3 \\
SV & 1.75 & 0.76 & 0.34 & 6.1 \\
HT2 & 1.75 & 0.79 & 0.15 & 2.8 \\
HT4 & 1.75 & 0.79 & 0.03 & 0.6 \\
RDM & 1.75 & 0.88 & 0.24 & 5.0 \\
SDM & 1.75 & 0.88 & 0.26 & 5.4 \\
RS & 1.75 & 0.87 & 0.01 & 0.2 \\
SPC & 1.75 & 0.88 & 0.26 & 5.4 \\
PS & 1.75 & 0.96 & 0.21 & 4.7 \\
PAE & 1.75 & 0.92 & 0.23 & 5.0 \\
PUE & 1.75 & 0.71 & 0.17 & 2.8 \\
PE & 1.75 & 0.82 & 0.16 & 3.1 \\
\hline
\end{tabular}

${ }^{\text {a }}$ Trait abbreviations explained in Table 1

\section{Discussion}

Genetic variation and performance of genotype groups in phosphorus-limited environments

There is substantial genetic variance for grain yield performance under $-\mathrm{P}$ among WA pearl millet openpollinated varieties which can be exploited in a breeding program. Reduction in GY and FD under -P as observed in the current study has been shown to be characteristic under $-\mathrm{P}$ stress in many crop plants (Atlin and Frey 1989; Wissuwa and Ae 2001; Manske et al. 2001; Chen et al. 2008; Cichy et al. 2008; Parentoni et al. 2010; Leiser et al. 2012; Gemenet et al. 2014). Landraces and improved open-pollinated varieties differed in a few traits. The observed later maturity in landraces under -P could also be confounded by higher sensitivity to photoperiod compared to improved varieties. Although not evaluated in the current study, Haussmann et al. (2007) found large genetic variation for photoperiod sensitivity in a wide range of WA landraces. In their study, they showed that late varieties tended to be more photoperiod sensitive. Photoperiod sensitivity has been said to have a possible role in adaptation to P-limited conditions in sorghum (Clerget et al. 2008; Leiser et al.
2014) and Arabidopsis thaliana (Nord and Lynch 2008). Leiser et al. (2014) found a higher P uptake of photoperiod-sensitive sorghum varieties under field conditions. Our finding of higher PS at an early growth stage for the landraces could be pointing towards this direction although it is not possible to fully extrapolate the findings from the pot experiment under the current study to the actual field performance due to the low genetic correlation between performance under pot conditions versus field conditions. The lack of difference in RGY under $-\mathrm{P}$ between the two groups is indicative that the difference in GY was mainly caused by other factors besides P. However, looking at only the top $10 \%$ genotypes selected based on RGY under -P, $60 \%$ were landraces. The fact that both landraces and openpollinated varieties could be selected under the best 10 genotypes implies that historical selections both by farmers and breeders have retained variations for performance under $-\mathrm{P}$ conditions and that selection gains can be achieved from using both groups as also reported for WA sorghum (Leiser et al. 2014).

Yield potential and phosphorus efficiency

Our evaluation fields for the current study had Bray-1 P values corresponding to what is frequently encountered in farmers' fields and which is below the critical $P$ value identified for this region ( $7 \mathrm{mg} \mathrm{P} \mathrm{kg}^{-1}$ soil; Manu et al. 1991; Doumbia et al. 2003). Genetic correlation between $-\mathrm{P}$ and $+\mathrm{P}$ location pairs obtained in the current study ranging from 0.63 to 0.91 are comparable to those reported for pearl millet testcrosses and inbred lines (ranging from 0.81 to 0.90 and from 0.87 to 0.96 respectively; Gemenet et al. 2014) and WA sorghum (Leiser et al. 2012) but are generally higher than those reported for maize and rape seed (Parentoni et al. 2010; Ding et al. 2012). High genetic correlation between $-P$ and $+\mathrm{P}$ performance implies that $\mathrm{GY}$ under $-\mathrm{P}$ is largely determined by yield potential rather than $P$ stress. Pearl millet grows in the harshest environments and is produced by some of the poorest of the world (Haussmann et al. 2012) under low input conditions. High negative nutrient balances (Stoorvogel and Smaling 1990) due to low fertilizer purchasing power of the farmers (Kochian 2012) with $P$ fertilizer application rates reported to be lower than $5 \mathrm{~kg} \mathrm{P} \mathrm{ha}^{-1}$ (Obersteiner et al. 2013) characterize pearl millet production systems in WA. The higher genetic correlations between $-\mathrm{P}$ and $+\mathrm{P}$ conditions observed for pearl millet indicate that pearl millet may be 
generally adapted to $-\mathrm{P}$ conditions in WA. Despite this possible adaptation, another likely explanation for the observed low differentiation between $-\mathrm{P}$ and $+\mathrm{P}$ is a masked $P$ effect as a result of many possible factors such as time of $\mathrm{P}$ fertilizer application (too late in some locations due to erratic rainfall, resulting in the $+P$ treatment being P-limited as well), drought stress, low soil $\mathrm{pH}$ as well as other constraining soil properties (Hash et al. 2002; Valluru et al. 2010; Gemenet et al. 2014). This is supported by the low RYR under $-P$ as observed across locations for pearl millet compared to other studies implying that our $-\mathrm{P}$ and $+\mathrm{P}$ treatments were not clearly differentiated despite adding a substantial amount of $\mathrm{P}$ to the $+\mathrm{P}$ treatment. Banziger et al. (1997) and Parentoni et al. (2010) showed that significant RYR (43 and $50 \%$ respectively) begun to occur with genetic correlations as low as $r_{g}=0.30$ in maize under low nitrogen $(\mathrm{N})$ and $-\mathrm{P}$ conditions respectively. It has been said that in less favorable agricultural production environments like Sahelian WA, interactions among drought, soil toxicity and nutrient availability have the capacity to mask economic responses to applied fertilizers or other soil amendments (Hash et al. 2002). Since only P and N were supplied in the current study, it is also possible that other soil chemical properties for instance $\mathrm{Al}$ and/or $\mathrm{Mn}$ toxicities or $\mathrm{K}, \mathrm{Ca}$, and/or $\mathrm{Mg}$ deficiencies led to the observed low differences between $-\mathrm{P}$ and $+\mathrm{P}$ treatments (Scott-Wendt 1988). Due to the low differentiation between $-\mathrm{P}$ and $+\mathrm{P}$, we used residual yields as described by Vadez et al. (2007) to represent the part of GY variation under -P that is not explained by yield potential i.e. RGY under $-\mathrm{P}$ as an estimate of PE. In our case, this would then represent the holistic effect of low soil P stress which is an interaction among many factors including drought, the soil physical and chemical environment as well as biological interactions. The genotypic differences observed for RGY under $-\mathrm{P}$ together with the significant positive correlation observed between GY under $-\mathrm{P}$ and RGY under $-\mathrm{P}$ implied that $\mathrm{P}$ efficient genotypes had better GY under $-\mathrm{P}$ conditions.

Relationship between flowering time and phosphorus efficiency

Generally, early flowering was positively associated with GY under both $-\mathrm{P}$ and $+\mathrm{P}$ conditions and this implies that pearl millet varieties in WA have been mainly selected to adapt to drought conditions through drought escape mechanism. The findings of positive correlation between early flowering and GY under both $-\mathrm{P}$ and $+\mathrm{P}$ conditions would imply that $\mathrm{P}$ stress has little effect on grain formation and that water availability at grain filling was the main decisive factor. However, the strong negative association between mean FD under $-\mathrm{P}$ and RF as observed across locations in this study indicates that water stress exacerbates the effects of low-P stress. This is further supported by the positive association between mean FD and mean RYR under -P conditions as reported in the present study. As suggested by one anonymous reviewer, drought would severely limit $\mathrm{P}$ availability on most soils, and a terminal drought would affect the $-\mathrm{P}$ treatment more severely if the typical P-deficiency-induced delay in flowering was observed. It has been shown that P uptake is reduced to near zero under drought stress (Hash et al. 2002; Sinclair and Vadez 2002) while P uptake is also highly correlated to grain yield performance under $-\mathrm{P}$ (Wang et al. 2010; Leiser et al. 2014; Gemenet et al. 2015). This therefore underlines the need to combine drought tolerance/escape with PE in WA pearl millet systems. Delay in flowering has been shown to be an adaptive mechanism in plants under $-\mathrm{P}$ conditions as it increases the duration of $\mathrm{P}$ uptake and if the delay is large enough, the genotype may catch up in P uptake under -P conditions (Nord and Lynch 2008; Karanam and Vadez 2010). However, the interaction between this adaptive mechanism and drought is not well understood. Understanding this interaction would be important for Sahelian WA because of its characteristic erratic rainfall and unpredictable droughts. We did not observe significant differences between tolerant and susceptible genotypes for FD under $-\mathrm{P}$ and it is also apparent from the results of the current study that the effects of FD under $-\mathrm{P}$ varied across environments. Beggi et al. (2014b) working with a 15-entry sub-set of the genotypes used in the current study in a lysimeter experiment observed that tolerant genotypes had shorter FD than susceptible ones. In their study, they found a high correlation between RGY and FD ( $r=-0.74 * * *)$ while we only had $r=$ $-0.15)$. This difference in results could be attributed to the less genetic variation for FD dealt with in the lysimeter study as well as to the sowing period since the said study was carried out between December and March (short days, but increasing day length) whereas the current study was evaluated in the usual growing season between July and October (longer days, but decreasing day length) implying that day-length differences might 
have an effect. It is therefore important to further study the relationships among drought tolerance, adaptation to $-\mathrm{P}$ conditions and photoperiodism in WA pearl millet. For instance, additive models incorporating FLO, FD under $-\mathrm{P}$ and $\mathrm{PE}$ explained between 61 and $78 \%$ of the total observed variation under $-\mathrm{P}$ across environments in the current study. This indicates the relative importance of considering all these traits in selection programs trying to adapt pearl millet to $-\mathrm{P}$ conditions. HI was not included in the additive model since it was found to be highly correlated with FLO and the two confounded each other in the model. Because HI is not quite independent of grain yield, FLO was considered a better measure for adaptation.

Relationship between early phosphorus efficiency and grain yield

We observed significant genetic variation for the various early growth vigor and PE-related traits measured under pot conditions, implying the possibility of selecting for $\mathrm{PE}$ at an early growth stage. Early growth of seedlings has been shown to be important for their establishment and eventual success in terms of biomass and grain yield (ter Steege et al. 2005). In pearl millet for instance, it has been shown that $\mathrm{P}$ availability is crucial during the first 30 days after sowing when panicle initiation and floral development occur. Deficiency of $\mathrm{P}$ at this stage is known to cause unrecoverable restrictions in development (Bidinger and Hash 2003; Valluru et al. 2010; Beggi et al. 2014b). We did not observe significant differences between tolerant and susceptible genotypes for PAE and PUE at early growth stage. Furthermore, we found that tolerant genotypes had lower PS as compared to susceptible genotypes. These findings are counterintuitive as we would normally expect tolerant genotypes to have higher PS, PAE and/or PUE than susceptible genotypes. This disparity in the findings from the current study and the expectations can be attributed to the low genetic correlation between traits measured in the pots and the actual field performance. In Gemenet et al. (2015) where early vigor was measured both under pot and field conditions, it was found that early vigor was more strongly positively correlated to grain yield under field conditions than under pot conditions. In addition, PAE and PUE measured on mature plants under field conditions were more strongly correlated to grain yield in the same study than those measured under pot conditions. We could partially attribute the lack of strong correlation between early vigor traits and grain yield to the fact that pearl millet openpollinated varieties are heterogeneous in nature (each plant has a different genotype), so replications in a pot trial with just a few plants per pot are no true replications, and the pot experiment may not have sampled most of the within-variety genetic variation as represented in the field trials. This heterogeneity has been historically selected for since it acts as a buffer against yield losses in the harsh Sahelian growing conditions (Haussmann et al. 2012) and pearl millet has been shown to have a high intra-varietal variation (Mariac et al. 2006). However, low correlation between traits measured in pots was also reported in pearl millet inbred lines under -P conditions (Gemenet et al. 2015) and sorghum evaluated for Striga hermonthica resistance (Omanya et al. 2004). The findings of the current study can therefore also be attributed to the 'artificiality' ascribed to pot experiments with regard to reduced soil quantity which in turn limits the amount of water and nutrients available to the plant in addition to impeding root growth (Passioura 2006; Whitmore and Whalley 2009; Poorter et al. 2012). Performance in the field on the other hand is conditioned by complex responses with a wide range of endogenous and exogenous signals that are integrated over the evolutionary and developmental life history of a genotype (Houle et al. 2010; Cobb et al. 2013). Pot evaluation of pearl millet for field performance under $-\mathrm{P}$ conditions should therefore be carried out only if it has comparative logistical advantage in terms of financial resources, time availability and selection intensity. Since we observed differences between locations as far as correlation between traits measured in pots and GY is concerned, the decision to evaluate in pots should also consider the objective of the evaluation, heritability of the trait as well as the target environment for which the trait is adaptive (Cobb et al. 2013; Araus and Cairns 2014; Gemenet et al. 2015).

Selection strategy for pearl millet targeting phosphorus-limited conditions

The observation of high genetic correlation between $-\mathrm{P}$ and $+\mathrm{P}$ field conditions and the not so large difference between response to direct selection under $-\mathrm{P}\left(20.1 \mathrm{~g} \mathrm{~m}^{-2}\right)$ and response to indirect selection under $+\mathrm{P}\left(16.3 \mathrm{~g} \mathrm{~m}^{-2}\right)$ in the present study implies that GY increases under $-\mathrm{P}$ conditions can be 
achieved by selecting in either $-\mathrm{P}$ or $+\mathrm{P}$ field conditions. This means that in future decisions need be made based on time and available resource on which strategy to follow. However, genotypes ranked differently in $-\mathrm{P}$ and $+\mathrm{P}$ conditions and indirect selection under $+\mathrm{P}$ conditions for performance under $-\mathrm{P}$ conditions would therefore leave out genotypes with specific adaptation to $-\mathrm{P}$ conditions. For instance, some of the best original landraces under $-\mathrm{P}$ conditions [PE02604 and PE00077] as well as Serkin_C2_Kandela_SMS, an improved variety derived from participatory breeding with women in Niger showed specific adaptations to $-\mathrm{P}$ conditions under the present study. Such landraces and improved varieties would be especially important as donor parental material to improve $\mathrm{P}$ efficiency of varieties that have already been improved for other traits like high yield potential. We also observed similar broad-sense heritability ( 0.73 for $-\mathrm{P}$ and 0.77 for $+\mathrm{P}$ ) implying that selection under $-\mathrm{P}$ can be carried out with the same precision as selection under $+\mathrm{P}$. Direct selection under $-\mathrm{P}$ conditions was reported to be more efficient in other crops such as oat (Atlin and Frey 1989, 1990), common bean (Beebe et al. 1997), rape seed (Ding et al. 2012), maize (Parentoni et al. 2010), sorghum (Leiser et al. 2012) and pearl millet testcrosses (Gemenet et al. 2014). With regard to secondary (indirect selection) traits measured under pot conditions, we observed some agreement for a few genotypes between pot and field performance especially for $\mathrm{P}$ efficiency traits. For instance some varieties selected under $-\mathrm{P}$ field conditions in the present study also performed well under pot conditions e.g. Serkin_C2_Kandela_SMS had high PAE and PUE. This indicates potential for using these early growth stage traits as secondary traits to indirectly select for high GY performance under -P field conditions. However, the usefulness of morphological and/or physiological traits as secondary (indirect selection) traits in a breeding program depends on their genetic correlation with grain yield, the extent of genetic variation, genotype-by-environment interaction and the cost of assessment (Mir et al. 2012). We observed very low genetic correlations between traits measured in pots and GY under $-\mathrm{P}$ field conditions. Consequently, response to selection was also lower than that obtained from selecting under field conditions. This therefore implies that the use of early vigor traits measured under pot conditions to select for GY performance under field conditions has limited applicability in pearl millet breeding activities targeting P-limited environments.

\section{Conclusions}

Pearl millet improvement for P-limited environments in WA is possible due to presence of genetic variation. Genetic gain is possible using either landraces or open-pollinated varieties. Residual yields under $-\mathrm{P}$ (i.e. the difference between the observed GY under $-\mathrm{P}$ and the estimated GY for $-\mathrm{P}$ from a linear regression between $-\mathrm{P}$ and $+\mathrm{P}$ yields can be used as proxy for $\mathrm{P}$ efficiency in combination with genotypic relative yield reduction in pearl millet. Selecting for early flowering varieties under $-\mathrm{P}$ combined with a moderate flowering delay under $-\mathrm{P}$ conditions (as a mechanism to increase duration of $\mathrm{P}$ uptake) is a possible breeding strategy targeting Plimited environments. Pearl millet varieties have different adaptation mechanisms to $-\mathrm{P}$ conditions and given the variability of growing conditions in WA as seen from single environments, it is important to maintain this adaptive variability. Using secondary traits measured at early growth stage in pot experiments for field performance under low-P conditions has limited applicability in WA pearl millet. Pearl millet varieties meant for low-P environments should be selected under low-P field conditions. Response to selection in pearl millet under low-P is relatively low due to the fact that $\mathrm{P}$ stress is confounded by various interactions with water stress, soil physical and chemical characteristics as well as soil biological aspects. Prospects are, however, high to improve pearl millet productivity under low-P conditions if breeding activities are combined with other systemsoriented research in order to make pearl millet production systems more sustainable.

Acknowledgments Two anonymous reviewers of this manuscript are greatly appreciated. Financial support from the German Federal Ministry for Economic Cooperation and Development (BMZ) for funding the phenotypic research through the BMZAbiotic Stress project (GIZ Project Number 09.7860.1-001.00) based at ICRISAT West Africa-Niamey, and the McKnight Foundation Collaborative Crop Research Program via discretionary research funds to BIG Haussmann is gratefully appreciated. The invaluable effort by technical staff at Sadore and collaborating NARS in Burkina Faso, Mali and Senegal for assisting in conducting the trials is also acknowledged. The publication is an output of a scholarship from the Food Security Centre of the University of Hohenheim, which is part of the DAAD (German Academic Exchange Service) program "exceed" and is supported by DAAD and BMZ. This publication was finalized as part of the CGIAR Research Program on Dry land Cereals. 


\section{References}

Araus JL, Cairns JE (2014) Field high-throughput phenotyping: the new crop breeding frontier? Trends Plant Sci 19(1):52-61

Atlin GN, Frey KJ (1989) Predicting the relative effectiveness of direct versus indirect selection for oat yield in three types of stress environments. Euphytica 44:137-142

Atlin GN, Frey KJ (1990) Selecting oat lines for yield in lowproductivity environments. Crop Sci 30:556-561

Banziger M, Betran FJ, Lafitte HR (1997) Efficiency of high nitrogen selection environments for improving maize for low nitrogen target environments. Crop Sci 37:11031109

Bashir EMA, Abdelbagi MA, Adam MA, Melchinger AE, Parzies HK, Haussmann BIG (2013) Characterization of Sudanese pearl millet germplasm for agro-morphological traits and grain nutritional values. Plant Genetic Res 1-13

Bashir EMA, Ali AM, Ali AM, Ismail MI, Parzies HK, Haussmann BIG (2014) Patterns of pearl millet genotypeby-environment interaction for yield performance and grain quality traits in Sudan. Field Crops Res 166:82-91

Bationo A, Christianson BC, Klaij MC (1993) The effect of crop residue and fertilizer use on pearl millet yields in Niger. Fert Res 34:251-258

Bationo A, Christianson BC, Baethgen WE, Mokwunye AU (1992) A farm-level evaluation of nitrogen and phosphorus fertilizer use and planting density for pearl millet production in Niger. Fert Res 31:175-184

Bayuelo-Jiménez JS, Ochoa-Cadavid I (2014) Phosphorus acquisition and internal utilization efficiency among maize landraces from the central Mexican high-lands. Field Crops Res 156:123-134

Beebe S, Lynch J, Galwey N, Tohme J, Ochoa I (1997) A geographical approach to identify phosphorus-efficient genotypes among landraces and wild ancestors of common bean. Euphytica 95:325-338

Beggi F, Falalou H, Buerkert A, Vadez V (2014a) Tolerant pearl millet (Pennisetum glaucum (L.) R. Br.) varieties to low soil $\mathrm{P}$ have higher transpiration efficiency and lower flowering delay than sensitive ones. Plant Soil. doi:10.1007/s11104014-2338-8

Beggi F, Haussmann BIG, Falalou H, Gemenet DC, Buerkert A (2014a) Early phosphorus efficiency of 102 pearl millet varieties from West Africa. In Beggi F (2014) Effects of Phosphorus and Water Stress on Shoot and Root Growth and on Mycorrhization of Different Pearl Millet (Pennisetum glaucum (L.) R. Br.) Varieties from West Africa. PhD dissertation, University of Kassel, Witzenhaussen, Germany

Bidinger FR, Hash CT (2003) Pearl millet. In: Nguyen HT, Blum A (eds) Physiology and biotechnology integration for plant breeding. New York, Marcel Dekker, pp 225-270

Birner R, Kone SA, Linacre N, Resnick D (2007) Biofortified foods and crops in West Africa: Mali and Burkina Faso. AgBioforum 10(3):192-200

Brück H, Sattelmacher B, Payne WA (2003) Varietal differences in shoot and rooting parameters of pearl millet on sandy soils in Niger. Plant Soil 251:175-185

Burton GW (1974) Factors affecting pollen movement and natural crossing in pearl millet. Crop Sci 14:802-805
Chen J, Xu L, Cai Y, Xu J (2008) QTL mapping of phosphorus efficiency and relative biologic characteristics in maize (Zea mays L.) at two sites. Plant Soil 313:251-266

Cichy KA, Snapp SS, Blair MW (2008) Plant growth habit, root architecture traits and tolerance to low soil phosphorus in an Andean bean population. Euphytica 165: 257-268

Clerget B, Dingkuhn M, Goze E et al (2008) Variability of phyllochron, plastochron and rate of increase in height in photoperiod-sensitive sorghum varieties. Ann Bot 101:579594

Cobb JN, DeClerck G, Greenberg A, Clark R, McCouch S (2013) Next-generation phenotyping: requirements and strategies for enhancing our understanding of genotype phenotype relationships and its relevance to crop improvement. Theor Appl Genet 126:867-887

Cooper M, Delacy IH, Basford KE (1996) Relationships among analytical methods used to analyze genotypic adaptation in multi-environment trials. In: Cooper M, Hammer GL (eds) Plant adaptation and crop improvement. CAB Int, Wallingford, pp 193-224

Cordell D, Drangert J-O, White S (2009) The story of phosphorus: global food security and food for thought. Glob Environ Chang 19:292-305

Cullis BR, Smith AB, Coombes NE (2006) On the design of early generation variety trials with correlated data. J Agric Biol Environ Stat 11:381-393

de Rouw (2004) Improving yields and reducing risks in pearl millet farming in the African Sahel. Agric Syst 81:73-93

Ding G, Zhao Z, Liao Y, Hu Y, Shi L, Long Y, Xu F (2012) Quantitative trait loci for seed yield and yield-related traits, and their responses to reduced phosphorus supply in Brassica napus. Ann Bot 109:747-759

Doumbia MD, Sidibé A, Bagayoko A, Diarra MA, Bationo A, Kablan RA, Yost RS, Hossner LR, Hons FM (2003) Recommandations specifiques d'1engrais: calibration et validation du module phosphore du modèle NuMaSS. Afr Crop Sci J 11:17-26

Falconer DS (1989) Introduction to quantitative genetics, 2nd edn. Longman, Harlow

FAO, IFAD, WFP (2013) The state of food insecurity in the world 2013. The multiple dimensions of food security. FAO, Rome

Gemenet DC, Hash CT, Sanogo MD, Sy O, Zangre RG, Leiser WL, Haussmann BIG (2015) Phosphorus uptake and utilization efficiency in West African pearl millet inbred lines. Field Crops Res 171:54-66

Gemenet DC, Hash CT, Sy O, Zangre RG, Sanogo MD, Leiser WL, Parzies HK, Haussmann BIG (2014) Pearl millet inbred and testcross performance under low phosphorus in West Africa. Crop Sci 54:2574-2585

Hash CT, Schaffert RE, Peacock JM (2002) Prospects for using conventional techniques and molecular biological tools to enhance performance of 'orphan' crop plants on soils low in available phosphorus. Plant Soil 245:135-146

Haussmann BIG, Boureima SS, Kassari IA, Moumouni KH, Boubacar A (2007) Mechanisms of adaptation to climate variability in West African pearl millet landraces - a preliminary assessment. J SAT Agric Res 3:1-3

Haussmann BIG, Rattunde HF, Weltzien-Rattunde E, Traore PSC, vom Brocke K, Parzies HK (2012) Breeding strategies for adaptation of pearl millet and sorghum to 
climate variability and change in West Africa. J Agron Crop Sci 198:327-339

Houle D, Govindaraju DR, Omholt S (2010) Phenomics: the next challenge. Nat Rev Genet 11:855-866

Hufnagel B, de Sousa SM, Assis L et al (2014) Duplicate and conquer: multiple homologs of PHOSPHORUSSTARVATION TOLERANCE 1 enhance phosphorus acquisition and sorghum performance on low-phosphorus soils. Plant Physiol 166:659-677

Jarvis A, Lau C, Cook S, Wollenberg E, Hansen J, Bonilla O, Challinor A (2011) An integrated adaptation and mitigation framework for developing agricultural research: synergies and trade-offs. Exp Agric 47:85-203

Karanam PV, Vadez V (2010) Phosphorus coating on pearl millet seed in low P Alfisol improves plant establishment and increases stover more than seed yield. Exp Agric 46:457-469

King KE, Lauter N, Lin SF, Scott MP, Shoemaker RC (2013) Evaluation and QTL mapping of phosphorus concentration in soybean seed. Euphytica 189:261-269

Knox JW, Hess TM, Daccache A, Perez Ortola M (2011) What are the projected impacts of climate change on food crop productivity in Africa and S Asia? DFID Systematic Review Final Report. Cranfield University. 77 pp

Kochian LV (2012) Plant nutrition: rooting for more phosphorus. Nature 488:466-467

Leiser WL, Rattunde HFW, Piepho HP, Weltzien E, Diallo A, Melchinger AE, Parzies HK, Haussmann BIG (2012) Selection strategy for sorghum targeting phosphorus limited environments in West Africa: analysis of multi-environment experiments. Crop Sci 52:2517-2527

Leiser WL, Rattunde HFW, Weltzien E, Haussmann BIG (2014) Phosphorus uptake and use efficiency of diverse West and Central African sorghum genotypes under field conditions in Mali. Plant Soil 377:383-394

Lynch JP (2011) Root phenes for enhanced soil exploration and phosphorus acquisition: tools for future crops. Plant Physiol 156:1041-1049

Manske GGB, Ortiz-Monasterio JI, van Ginkel M, Gonzalez RM, Fischer RA, Rajaram S, Vlek PLG (2001) Importance of P uptake effi ciency versus $P$ utilization for wheat yield in acid and calcareous soils in Mexico. Eur J Agron 14:261-274

Manu A, Bationo A, Geiger SC (1991) Fertility status of selected millet producing soils of West Africa with emphasis on phosphorus. Soil Sci 152:315-320

Mariac C, Luong V, Kapran I, Mamadou A, Sagnard F, Deu M, Chantereau J, Gerard B, Ndjeunga J, Bezancon G, Pham J-L, Vigouroux Y (2006) Diversity of wild and cultivated pearl millet accessions (Pennisetum glaucum [L.] R. Br.) in Niger assessed by microsatellite markers. Theor Appl Genet 114: $49-58$

Mir RR, Zaman-Allah M, Sreenivasulu N, Trethowan R, Varshney RK (2012) Integrated genomics, physiology and breeding approaches for improving drought tolerance in crops. Theor Appl Genet 125:625-645

Nord EA, Lynch JP (2008) Delayed reproduction in Arabidopsis thaliana improves fitness in soil with suboptimal phosphorus availability. Plant Cell Environ 31:1432-1441

Obersteiner M, Peñuelas J, Ciais P, van der Velde M, Janssens IA (2013) The phosphorus trilemma. Nat Geosci 6:897-898

Omanya GO, Haussmann BIG, Hess DE, Reddy BVS, Kayentao M, Welz HG, Geiger HH (2004) Utility of indirect and direct selection traits for improving Striga resistance in two sorghum recombinant inbred populations. Field Crops Res 89: 237-252

Parentoni S, de Souza JC, de Carvalho AV et al (2010) Inheritance and breeding strategies for phosphorus efficiency in tropical maize (Zea mays L.). Maydica 55:1-15

Passioura JB (2006) The perils of pot experiments. Funct Plant Biol 33:1075-1079

Piepho H-P, Möhring J (2007) Computing heritability and selection response from unbalanced plant breeding trials. Genetics 177:1881-1888

Poorter H, Bühler J, van Dusschoten D, Climent J, Postma JA (2012) Pot size matters: a meta-analysis of the effects of rooting volume on plant growth. Funct Plant Biol 39:839850

Pucher A, Hogh-Jensen H, Gondah J, Hash CT, Haussmann BIG (2014) Micronutrient density and stability in West African pearl millet-potential for biofortification. Crop Sci 54: $1709-1720$

Rai KN, Govindaraj M, Rao AS (2012) Genetic enhancement of grain zinc and iron content in pearl millet. Qual Assur Saf Crops Foods 4:119-125

Rai KN, Patil HT, Yadav OP, Govindaraj M, Khairwal IS, Cherian B, Rajpurohit BS, Rao AS, Shivade H, Kulkarni MP (2014) Pearl millet variety Dhanashakti. Indian J Genet 74(3):404 407

Ramaekers L, Remans R, Rao IM, Blair MW, Vanderleyden J (2010) Strategies for improving phosphorus acquisition efficiency of crop plants. Field Crops Res 117:169-176

Rebafka FP, Bationo A, Marschner H (1993) Phosphorus seed coating increases phosphorus uptake, early growth and yield of pearl millet (Pennisetum glaucum (L.) R. Br.) grown on an acid sandy soil in Niger, West Africa. Fert Res 35:151-160

Scott-Wendt J (1988) Variability in pearl millet (Pennisetum americanum) fields in semi-arid West Africa. Arid Soil Res Rehabil 2:49-58

Sinclair TR, Vadez V (2002) Physiological traits for crop yield improvement in low N and P environment. Plant Soil 245:115

Stoorvogel JJ, Smaling EMA (1990) Assessment of soil nutrient depletion in sub-Saharan Africa: 1983-2000, vol 1, Main Report. The Winand Staring Centre, Wageningen

Supriya A, Senthilvel S, Nepolean T, Eshwar K, Rajaram V, Shaw R, Hash CT, Kilian A, Yadav RC, Narasu ML (2011) Development of a molecular linkage map of pearl millet integrating DArT and SSR markers. Theor Appl Genet 123: 239-250

ter Steege MW, den Ouden FM, Lambers H, Stam P, Peeters AJM (2005) Genetic and physiological architecture of early vigor in Aegilops tauschii, the D-Genome donor of hexaploid wheat. A quantitative trait loci analysis. Plant Physiol 139: 1078-1094

Vadez V, Kholova J, Yadav RS, Hash CT (2013) Small temporal differences in water uptake among varieties of pearl millet (Pennisetum glaucum (L.) R. Br.) are critical for grain yield under terminal drought. Plant Soil 371: 447-462

Vadez V, Krishnamurthy L, Gaur PM, Upadhyaya HD, Hoisington DA, Varshney RK, Turner NC, Siddique KHM (2007) Large variation in salinity tolerance is explained by differences in 
the sensitivity of reproductive stages in chickpea. Field Crop Res 104:123-129

Valluru R, Vadez V, Hash CT, Karanam P (2010) A minute phosphorus application contributes to a better establishment of pearl millet (Pennisetum glaucum (L.) R.Br.) seedling in phoshorus deficient soils. Soil Use Manag 26:36-43

Velu G, Rai KN, Muralidharan V, Longvah T, Crossa J (2011) Gene effects and heterosis for grain iron and zinc density in pearl millet (Pennisetum glaucum (L.) R. Br). Euphytica 180: 251-259

Veneklaas EJ, Lambers H, Bragg J, Finnegan PM, Lovelock CE, Plaxton WC, Price CA, Scheible WR, Shane MW, White PJ, Raven JA (2012) Opportunities for improving phosphorus use efficiency in crop plants. New Phytol 195:306-320
Venuprasad R, Laffitte HR, Atlin GN (2007) Response to direct selection for grain yield under drought stress in rice. Crop Sci 47:285-293

Wang X, Shen J, Liao H (2010) Acquisition or utilization, which is more critical for enhancing phosphorus efficiency in modern crops? Plant Sci 179:302-306

Whitmore AP, Whalley WR (2009) Physical effects of soil drying on roots and crop growth. J Exp Bot 60:2845-2857

Wissuwa M, Ae N (2001) Genotypic variation for tolerance to P deficiency in rice and the potential for its exploration in rice improvement. Plant Breed 120:43-48

Wissuwa M, Mazzola M, Picard C (2009) Novel approaches in plant breeding for rhizosphere-related traits. Plant Soil 321: 409-430

Wricke G, Weber E (1986) Quantitative genetics and selection in plant breeding. Walter de Gruyte \& Co, Berlin 